\title{
A means to an industrialisation end? Demand side management in Nigeria
}

\section{Article}

\section{Accepted Version}

Creative Commons: Attribution-Noncommercial-No Derivative Works 4.0

Ikpe, E. and Torriti, J. (2018) A means to an industrialisation end? Demand side management in Nigeria. Energy Policy, 115. pp. 207-215. ISSN 0301-4215 doi:

https://doi.org/10.1016/j.enpol.2018.01.011 Available at https://centaur.reading.ac.uk/74864/

It is advisable to refer to the publisher's version if you intend to cite from the work. See Guidance on citing.

To link to this article DOI: http://dx.doi.org/10.1016/j.enpol.2018.01.011

Publisher: Elsevier

All outputs in CentAUR are protected by Intellectual Property Rights law, including copyright law. Copyright and IPR is retained by the creators or other copyright holders. Terms and conditions for use of this material are defined in the End User Agreement.

\section{www.reading.ac.uk/centaur}

\section{CentAUR}

Central Archive at the University of Reading

Reading's research outputs online 


\section{A means to an industrialisation end? Demand Side Management in Nigeria}

Eka Ikpe

African Leadership Centre, King's College London, Strand, London, WC2R 2LS, UK

Jacopo Torriti*

School of the Built Environment, University of Reading, Whiteknights Campus, Reading, RG6 6AY, UK

\section{Abstract}

Electricity is essential for economic development and industrialisation processes. Balancing demand and supply is a recurrent problem in the Nigerian electricity market. The aim of this work is to assess the technical and economic potential of Demand Side Management (DSM) in Nigeria given different future levels of industrialisation. The paper places industrialisation at the centrefold of the appraisal of DSM potential in Nigeria. It does so by designing industrialisation scenarios and consequently deriving different DSM penetration levels using a cost-optimisation model. Findings show that under the high industrialisation scenario by the year 2050 DSM could bring about 7 billion USD in cumulative savings thanks to deferred investment in new generation and full deployment of standby assets along with interruptible programmes for larger industrial users. The paper concludes by providing policy recommendations regarding financial mechanisms to increase DSM deployment in Nigeria. The focus on DSM serves to shift the policy debate on electricity in Nigeria from a static state versus market narrative on supply to an engagement with the agency and influence on industrial end-users.

\section{Keywords}

Demand Side Management; Electricity; Industrialisation; Nigeria

\footnotetext{
*Corresponding author, Email: j.torriti@reading.ac.uk, Telephone: +44 (0) 1183788196.
} 


\section{Introduction}

Electricity is an essential element of economic progress in the developing world. Energy use has accompanied economic development on account of a range of factors including industrialisation (Narayan and Smyth, 2009). This point supports an extant logic of the importance of modern energy sources for the manufacturing sector. Indeed, Ebohon (1996) and Templet (1999) have argued that energy is a necessary complement to labour and capital for production processes. The significance of access to electricity is also very relevant to contemporary debates on sustainable development. Menegaki and Tugcu (2016) suggest that limited access to modern energy sources is cited as a main obstacle to the achievement of sustainable development in Africa.

In Nigeria, the lack of electrification has been pointed out as a main factor undermining economic development and the expansion of industrialisation (Akinlo, 2009). Yet, the country features significant opportunities for further electrification and higher industrialisation. Much attention has been paid in research to the problems associated with generation and transmission systems in Nigeria. For instance, it has been pointed out that generation is low for the most populous country in Africa (Aliyu et al, 2013) and that the transmission network lacks the level of investment required to cover the size of the country (Adenikinju, 2005). The challenges of balancing electricity demand and supply in Nigeria are recognised as large cost drivers and have significantly negative environmental connotations.

The relationship between industrialization and electrification is complex. One the one hand, industrialisation can facilitate further electrification. This was certainly the case in the independence period in Nigeria, as industrial development progressed from the 1950s to the mid-1960s leading to increased electricity generation of about 20\% per annum to meet demand (Kilby, 1969: 104-105). More recently, expanding electrification in response to industrial development is especially evident with small-scale private electricity generation systems. However, these are renowned for high production costs burdens that impact negatively on competitiveness. On the other hand, 
electrification can underscore improved industrial development. For Nigeria, Yahaya et al (2015) find that manufacturing output is reliant on stable and adequate access to electricity especially in the long-run. Against this background, the Nigerian state is attempting redress the challenge of access to electricity especially given its significance to industrialisation (Chete et al, 2014).

Much focus on addressing the problems presented by inadequate access to electricity in Nigeria are concerned with supply-side initiatives (Akinlo, 2009; Yahaya et al, 2015). Yet, a set of solutions from the demand side -also known as 'Demand Side Management' (DSM) - could prove more costeffective than some new generation developments. DSM could address insufficient power supply against the background of intended expansion of industrial activities. Steep increases in demand may occur mainly due to large industrial end-use. Industrialisation is likely to trigger the dual effect of increasing the need for reliable supply whilst offering back flexibility in the form of DSM.

The aim of this paper is to assess the technical and economic potential of DSM in Nigeria given different future levels of industrialisation. In developing as well as developed countries, DSM has been operated mainly by utilities using industrial end-users as the main enablers. The history of the Nigerian electricity market shows that the steepest increases in electricity demand historically have been associated with changes in industrialisation processes. Contemporary reflections also highlight the reliance of industrial expansion on electricity access. . For these reasons, the paper places industrialisation at the centrefold of the appraisal of DSM potential in Nigeria. It does so by designing industrialisation scenarios and consequently deriving different DSM penetration levels in the future using a cost-optimisation model.

After this introduction, the paper provides background information around the role of DSM for electricity systems in developing countries (Section 2); highlights the history of balancing demand and supply in the electricity market in Nigeria (section 3); describes the methodology underpinning this work (Section 4); presents findings from a cost-optimisation model runs (Section 5); and 
concludes by discussing findings on the dynamics between industrialisation and demand-side measures and presenting potential policy options for incentivising DSM in Nigeria (Section 6).

\section{Demand Side Management in developing countries}

\subsection{Demand Side Management: definition, objectives and measures}

DSM can be defined as a wide ranging actions to reduce demand for electricity (or gas) and/or to shift demand from peak to off peak times (International Energy Agency, 2011). Traditionally, objectives associated with DSM were generally restricted to efficiency and conservation programmes. Hence, the measures were mainly focused on energy efficiency, including more efficient light bulbs (as explained in the case of Nigeria in Section 3.3).

With time DSM objectives encompassed programs emphasising price response as well as automated reductions in energy at peak times (Bradley et al, 2013). Corresponding measures include Demand Response (i.e. any reactive or preventative method to reduce, flatten or shift peak demand) and load management (i.e. advance or delay appliance operating cycles by a few seconds to increase the diversity factor of the set of loads). For utilities, both reducing and shifting electricity demand implies avoiding or delaying building additional generation capacity. In some situations, this would avoid or defer electricity price increases that would otherwise be imposed on customers to finance new investments in system capacity. Industrial plants are often targeted for DSM as they are able to reduce overall demand by adopting efficiency measures. Several industrial users can also shift consumption away from peak demand over relatively long time periods, depending on the processes used.

\subsection{DSM implementation}


DSM plays a vital role in integrated planning for energy systems in both developed and developing countries.

In principle, DSM was implemented as part of integrated planning in developing countries in the 1980s (Gellings, 1985). In both developed and -increasingly so- developing economies, environmental concerns of energy use and economic development became a major concern and the environmental dimension dominated the policy debate. This brought a major shift in the focus of DSM as well- the issue of local, regional and global environmental effects of energy use became an integral part of the picture. In the 1990s, liberalisation of energy markets and restructuring affected the entire world. Initially increased optimism over competitive pricing deflated DSM of its original value, but by the end of the century increased concerns about security of supply gave DSM new life. Climate change and other global and local environmental issues were also part of the picture. These changes brought new issues and challenges to the attention and by the end of the century, it became evident that unless the fundamental design, including DSM, is well thought through, liberalisation of energy market cannot achieve the expected results. In the first decade of the 2000s, the focus shifted to high oil prices, energy scarcity and the debate over state intervention as opposed to market-led energy supply. Concerns around security of supply, the return of the peak oil discussion in a carbon-constrained world caused much of this shift in the policy debate. Looking at the future of peak demand, a number of studies around the end of the first decade of the century set the scene for a future which is more and more challenging in terms of peak electricity demand which will have to deal with increased load from heat pumps and electric cars.

In practice, challenges around DSM implementation consist of lack of awareness about energy efficiency in consumers and insufficient auditing. For example, several industrial and commercial companies still have not carried out energy audits to collect reliable information on their current operations. While this may be due to a failure by management to appreciate the potential benefits 
of energy efficiency, some companies miss skilled personnel able to perform audits (United Nations Industrial Development Organisation, 2015).

DSM has been seen as an aid to deficient power supply in developing countries and specifically in India (Mukhopadhyay \& Rajput, 2010) and China (Zhong et al, 2010). An example of DSM implementation extremely relevant to Nigeria consists of Brazil. Like Nigeria, this country has a generation fleet consisting primarily of hydro and thermal power. DSM has been deployed to defer new investments in distribution and transmission networks, and reduce the necessity of complementary thermal power operation during peak periods (Boshell \& Veloza, 2008). In Mexico, a centralised, government-led initiative on DSM generated direct savings of $1.5 \mathrm{GW}$ in electricity demand (ADEME, 2004).

\section{History of balancing demand and supply in the Nigerian electricity market}

\subsection{The electricity market in Nigeria: A brief history}

Balancing demand and supply is a recurrent problem in the Nigerian electricity market. Interruptions in electricity supply are frequent and pose continuous stress to the grid. Issue with balancing electricity demand and supply in Nigeria are not new and found different solutions over the years. In the 1950s electricity demand in Nigeria was lower than supply. However, with industrial development, the demand for electricity gradually increased and later exceeded supply (Makwe et al, 2012). The rapid growth in electricity demand was countered initially by rising generation $(20 \%$ increase per year on average between 1956 and 1965) alongside declining costs of generation from 1956 to the early 1960s (Kilby, 1969: 104-105). However, improvements in generation were not long-lived. Rather, instability and unplanned interruptions of supply from 1962 revealed the challenge to the capacity of provision. Electricity was an important input for industry and advancing structural transformation agenda that was emerging under the First development plan of 1962- 
1968. At this time, electricity was especially important for the development of the textiles and cement sectors (Adenikinju, 1998). However, the imbalance between supply and demand of electricity with particular reference to the manufacturing sector is a pattern that has remained to date.

Until its reform in 2005, when it was transformed into the Power Holding Company of Nigeria (PHCN), the Nigerian Electric Power Authority functioned as a government-controlled and vertically integrated monopoly responsible for power generation, transmission, and generation. PHCN was subsequently unbundled into 6 generators, 11 distributors and one transmission company. These companies are responsible to carry out the functions relating to the generation, transmission, trading, distribution and bulk supply as well as resale of electricity (NTWG, 2009).

In the early 2000s the electricity market had installed capacity of over $8 \mathrm{GW}$ and experienced frequent blackouts leading to a loss of up to 65 percent of working hours in manufacturing companies which could not afford their own electricity generating sets (Adenikinju, 2003). From a survey carried out across the manufacturing sector Adekiniju (2003) shows that manufacturers across different regions, high technology- and low technology-use sectors as well as scales of operation cite electricity supply as the most important challenge to their activities. Bazilian and Onyeji (2012) echo this finding. Okafor (2008) argued that the demise of local manufacture across a range of sectors, namely chalk, wax candle production, dry cell and automobile batteries as well as the decline in automobile assemblage, textiles, cables, paint, steel and petrochemicals over $2000-$ 2007 is attributable to deficiencies in energy supply and use among other factors. For firms that acquire electricity generating sets the associated costs can be enormous. Steinbuks and Foster (2010) show that 20 percent of installed capacity in Nigeria is based on self-generation and these systems are generally more expensive than electricity provision from the public grid. The Manufacturing Association of Nigeria estimates energy costs as comprising 36 percent of total manufacturing production costs. The true scale of the challenge is clearer when it is compared to 
6.45 percent equivalent in the European Union (Gardiner, 2016). The result of such high costs, particularly as compared with other contexts is a lower level of competitiveness of goods produced both domestically and for exports. Steinbuks and Foster (2010) make the point that this adds to the capital operating and production costs thus limiting investment options that are available to firms. This is expected to have a detrimental impact on innovation and the uptake of improved science and technology approaches that should advance the industrialisation process.

\subsection{Recent outlook of the Nigerian electricity market}

Electricity generation consists of a mix of hydro and thermal power with the thermal generation being based primarily on gas (Energy Commission of Nigeria, 2012). The demand for electric power is increasing at a high rate particularly in urban areas. With an estimated yearly economic growth rate of between seven per cent and 13 per cent, as well as an urbanisation rate of 3.8 per cent, Nigeria's electricity demand has been projected to grow from 15 GW in 2016 to 41 GW by 2018 and 88 GW by 2020 respectively according to Eko Electricity Distribution Company. However, these estimates seem to take into account linear economic and population growth only, without the cost constraints currently facing the Nigerian electricity network, especially in terms of connecting rural areas. The Nigerian government estimates that at least half of the population is not connected to the electricity grid and most of those not connected are in rural areas (Presidency of Federal Republic of Nigeria, 2010). The Nigerian government estimates that in order to achieve the goals of its latest development plan (Vision 2020) of making Nigeria one of the 20 largest economies in the world by 2020 , it will require an installed electricity generating capacity of at least $40 \mathrm{GW}$ by 2020 . According to the installed capacity peaked in 2010 (31 GW), but was down to 21 GW in 2012.

Privatisation of the electricity sector in Nigeria has been long considered as a means of resolving its challenges and yielding expected outcomes of optimised generation to address vast demand requirements. It is against this background that in 2005 the Electric Power Sector Reform Act 
articulated the process of privatisation and unbundling through supporting Independent Power Projects (Dada 2014). But results have been judged widely as mixed or indeed disappointing (Quaghe, 2017; Business Day 2017). Attempts at transformation of the electricity sector through privatisation are informing also engagement with renewable sources as a foundation for electricity production especially with reference to solar energy, bio-fuels, wind and hydro-power. The National Renewable Energy and Energy Efficiency Policy is replete with references to private sector leadership for investment and development of the sector (ECN, 2014). However, there is reference also to an anticipated increasing role for indigenous private capital alongside the value of public-private collaborative engagements. Against this background, Nigeria acceded to the Paris Climate change agreement which came into force in October 2016 and subsequently articulated efforts to promote compliance at COP22 in Marrakech November 2016 that includes prioritising clean energy solutions especially solar energy, bio-fuels, wind and hydro-power and prioritising large-scale deployment of low-carbon technologies (Federal Government of Nigeria, 2016).

Recent solutions to the supply and demand balancing problem involve the massive penetration of renewable sources of energy, such as wind (Ohunakin et al, 2011), but also nuclear (Ejiogu, 2013). However, in research not so much attention has been paid to managing demand in Nigeria. The starting point of this work is that a significant upgrade of the Nigerian electricity system depends on the level of industrialisation the country will experience and, in turn, the penetration of DSM as a tool to improve flexibility of demand and grid reliability.

\subsection{DSM in Nigeria}

The Nigerian Electricity Regulatory Commission has regulatory leadership on DSM matters and has, thus far, developed two main programmes. The Nigerian Electricity Regulatory Commission (2014) considered that lighting alone could reduce between $3 \mathrm{GW}$ and $4 \mathrm{GW}$ electricity consumption at peak time through bulb replacement. Peak demand was $4.1 \mathrm{GW}$ on average in 2014 , but was 
forecasted to increase to $14.63 \mathrm{GW}$ in following years. In 2016, the Nigerian Electricity Regulatory Commission decided to widen publicity on energy saving DSM with regards to the benefits of using Compact Florescent Lamps, which are expected to decrease peak loads by up to 60 percent. In addition to lighting, the main DSM policy in Nigeria consists of rolling out electricity meters and smart meters for future DSM programmes. Currently, the metering level in Nigeria is about $50 \%$ of the customer population.

With regards to DSM for industrial users, for high energy consumer sectors (transport, power sector, agriculture) DSM technologies will be progressively introduced, including peak load management when possible. Compared with the current level, it is foreseen that energy efficiency and DSM will increase by at least $20 \%$ by 2020 and $50 \%$ by 2030 (Se4all, 2016).

Historically, a fraction of the residential sector in Nigeria has owned flexible demand and stand-by generation assets. For instance, middle and higher income Nigerian households own diesel generators to offset interruptions in electricity supply (Lee and Anas, 1989). More recently, diesel stand-by generation, which has high capital costs, high fuel running costs, high levels of noise and localised pollution, has been increasingly replaced or supplemented by small-size electricity storage (Azoumah et al, 2011). Similarly, in order to offset power outages, the commercial and industrial sectors have historically been using privately operated petrol or diesel generators to meet their own demand.

\section{Methodology}

The methodological approach of this paper consists of two main steps. First, stylised industrialisation scenarios are defined based on available literature. Secondly, a cost optimisation model for electricity systems is run based on three industrialisation scenarios. 
We derive three scenario of industrialisation in Nigeria based on the work on drivers for electricitydemand projections by Ibitoye \& Adenikinju, (2007). The three scenarios of high, medium and low industrialisation are based on the Nigerian industrial sector achieving in the future milestones such as: (i) attaining the status of an industrializing country in 2020; (ii) transforming from low- to middleincome economy; and (iii) achieving the Millennium Development Goals requirements by 2020. These milestones are operationalised in terms of: (i) migrating from low income to middle-income economy; (ii) improving PCl to ensure poverty reduction; and (iii) improving electricity access, from the level of $45 \%$ in 2005 to $73 \%$ in 2020 (i.e. reduce the population without access by half in 2020 ) as illustrated in Table 1.

Table 1 here

MARKAL is a well-known dynamic linear programming model incorporating a full range of energy processes, e.g. exploitation, conversion, transmission, distribution and end-use. The model represents energy producing and consuming sectors in a reference energy system network that links resource supplies, energy conversion and processing technologies, and end-use demands and the devices that meet them, tracking the flows of energy and associated emissions. It can consider existing as well as advanced technology that may be deployed in future. The objective function includes the capital costs of energy conversion technologies, capital costs of end-use technologies, fuel costs, infrastructure costs, and operating and maintenance costs. MARKAL searches for a leastcost combination of supply-side technologies and demand-side programmes which interact dynamically over a set period of time. The model produces outputs which are least-cost paths subject to constraints that enforce network integrity by performing a perfect information minimisation of the net present value of total energy system costs, including the capital and operating costs. In the elastic demand formulation (Loulou and Lavigne, 1996), used in this paper to 
examine the impacts of industrialisation scenarios, the objective function also includes any consumer welfare gain resulting from a decrease in demand in response to system congestions and peaks. In a typical MARKAL application, energy demand is represented at a detailed, end use, energy service demand level, and fuel consumption levels are determined by the model, calculated by allowing different fuels and devices to compete to service end-use demands (Fishbone \& Abilock, 1981). This approach allows the evaluation of supply side options against costs and incentives for efficient demand side technologies. However, because of the lack of end use data, and in order to substantially shorten model construction time, the Nigeria MARKAL model developed in this paper focused on the supply and power sectors only, representing electricity demand growth in a simple summary fashion as a single demand with a simplified time-of-use load curve. This design allowed evaluation of DSM investment options against a multiplicity of industrialisation scenarios.

Statistical information on generation, transmission and distribution of electricity are published in PHCN Annual Reports and Accounts. Moreover, time-series data on electricity production and consumption are derived from the Annual Abstract of Statistics, published by the National Bureau of Statistics (2016), and the Economic and Financial Review published by the Central Bank of Nigeria (2015).

In this analysis DSM encompasses a wide range of demand-side initiatives, including stand-by generation, which as noted in section 5 is extremely abundant in Nigeria especially for industrial and commercial end-users, demand side response in correspondence of peaks and interruptible programmes for larger industrial consumers. In the MARKAL modelling DSM is operationalised taking into account interruptible loads from industrial end-users and connection of existing standby generation from commercial and industrial users (more detail in Section 5). Interruptible load leads to consumers turn off portions of their load for specified periods of time. However, the most common strategy is the use of backup generators during the interruptible event. Therefore, we are 
only considering the case where the utility undergoes a decrease in the supplied electricity because customers stop consuming or they are using their own generation.

\section{Assessing the potential of DSM in Nigeria}

\subsection{Modelling industrialisation scenarios}

The modelling results for the high, medium and low industrialisation scenarios are summarized in Table 1. During the period from 2005 to 2050, the final energy consumption in Nigeria is expected to increase from 1780 to $2073 \mathrm{PJ}$ for the medium industrialisation scenario with industrial in the total energy consumption increasing from 368 to 497 PJ, i.e. from $20 \%$ to $24 \%$. In the low industrialisation scenario final energy consumption in 2050 will be 1696 PJ with industry decreasing to 275 PJ due to higher efficiency of existing and new installation plants combined with an increase in imports. This takes into account an increase in imports from the current base of $10.8 \%$ of GDP (equivalent to over 7 billion Nigerian Naira per year at the end of 2016) which consist of manufactured goods, machinery and transport equipment, chemicals, and food and live animals. Under the high industrialisation scenario, final energy is expected to raise to 2748 PJ by the year 2050, with industry reaching 894 PJ. The increase in industry sector's final energy consumption is attributed to a mix of energy efficiency improvement, and in particular to increased value-added share of industry in GDP as well as structural adjustments of both industrial branches and products.

Table 2 here

Figure 1 shows the MARKAL forecast for increases in electricity demand under high, medium and low industrialisation scenarios. Under a low industrialisation scenario Nigeria could experience years 
with reductions in electricity demand, partly because of improvements in energy efficiency and partly to the reduction of economic activity. Unlike final energy in Table 2 which takes 2015 as the base year, increases in electricity demand take 2010 as the base year. This is because 2012 is the last PHCN Annual Report we could get hold of.

Figure 1 here

Table 3 here

The lifetimes of these plants were revised downward from international standards. A sunset date of 2024 (model year 2025) is assumed for the current cohort of power plants in Table 3. In the case that sufficient investment capital to replace these plants is not available, the present practice of repairing and upgrading these plants sufficiently to keep them operating may continue. This approach yielded costs very similar to those for the proposed new plants, which are based on international values (IEA, 2015). This similarity suggests that these values do not include elevated maintenance costs due to the condition of the plants and the burning of domestic crude.

An estimate of the cost of these repairs is embedded in the calculations for Figure 2, which shows the annual system costs of electricity generation, transmission and distribution up to 2050 without the implementation of DSM measure. 
Figure 2 here

\subsection{Electricity demand development by industrial sector}

Figure 3 and Figure 4 show the Industrial electricity demand development by type of industry under medium and high industrialisation scenarios 2005, taking as the baseline year. The increase in electricity demand from chemical, iron steel, non-ferrous metal, pulp-paper industries is paired with higher efficiencies in transmission network. In other venues the oil sector is at times considered part of the industrial sector. Following years in which the sector's share of the GDP was high -standing at 17.52 per cent, 15.89 per cent and 14.40 per cent for 2011, 2012 and 2013, respectively- the oil sector has declined to 3 per cent as a percentage of GDP (World Bank, 2017). This can be mainly attributed to the re-basing of Nigerian GDP. However, the oil sector is excluded in this analysis as it does not represent manufacturing end-users.

In the high industrialisation scenario, the increase in large industrial production is paired with other industry, which could comprise a combination of textile and other industries.

Figure 3 here

Figure 4 here

Figure 5 shows trends in services consumption for all energy demand sectors in the high industrialisation scenario. The modelling work shows a steady increase in hot water and cooking services. This is due to higher levels of electrification of the residential sector thanks to the provision of grid, mini-grid and off-grid distribution networks. The cooling industry is expected to grow 
significantly until 2025. The Southern region of the country is the key revenue generating region in the overall cooling market. Urban areas in particular have seen a steady increase of air conditioning units at times of economic growth (Research and Markets, 2016). However, over time the high demand for cooling, which is inevitably high in a developing economy with a tropical climate, is expected to bring about an increase in efficiency also thanks to better home (and office) insulation. This will lead to a reduction in cooling services by 2025 followed by an upward trend in 2040 due to a decrease in price of air conditioning devices and a second wave of cooling services penetration from urban-only to non-urban areas. In modelling services we did not take into account increases in temperature from climate change.

Figure 5 here

Figure 6 and Figure 7 illustrate respectively in physical units (PJ) and percentages primary energy mix for the three scenarios in the year 2050. The scenarios are built taking into account the vast array of conventional energy-resources, including crude oil, natural gas, coal and tar sands. In addition, there is substantive potential for renewable energy-resources such as hydro, solar, wind, biomass, wave and tidal, and some geothermal. As a starting point for estimating the current technical potential of energy mix sources the following figures were considered from OPEC (2011) and Energy Commission of Nigeria (2002): crude oil (36 billion barrels); natural gas (185 trillion cubic feet); hydro power (14,750 MW); coal (2.75 billion metric tons); solar radiation (3.5-7.0 kWh/m2-day); wind energy 2.0$4.0 \mathrm{~m} / \mathrm{s}$; biomass (144 million tons/year); and wave and tidal energy 150,000 TJ/year).

\subsection{Modelling DSM and comparing scenarios with and without DSM}

DSM penetration levels take into consideration both interruptible loads from the industrial sector as well as assumed standby generation from commercial and industrial users. Percentages on 
interruptible industrial loads by industrial sector were taken from Grünewald and Torriti (2013) with volumes associated to different sectors from the MARKAL model. Standby generation (which consists mostly of diesel and petrol sets) is based on the $20 \%$ installed capacity average for Africa from a study by Steinbuks and Foster (2010).

The moderate penetration of nuclear foreseen for medium and high industrialisation scenarios is not matched in the low industrialisation scenario. This is because under higher levels of industrialisation the government is more likely to fund larger nuclear developments which could ensure a constant low-carbon baseload. The government initiated a Nuclear Power Project and announced a National Nuclear Power Roadmap which aims at generating 1 GW of electricity by 2020 and 4 GW by 2030 from nuclear power (Presidency of Federal Republic of Nigeria, 2010).

Figure 6 here

Figure 7 here

Figure 8 shows the costs of different industrialisation scenarios with DSM penetration levels from Figure 7. The main finding is that low levels of industrialisation do not yield significant cost savings. Between 2015 and 2035 the increase in annual system costs is higher for the low industrialisation scenario than for the medium industrialisation scenario. This is because the presence of more industrial end-users allows higher access to DSM opportunities, for instance thanks to the presence of flexible loads in lighting, air ventilation, refrigeration and load interruptible industrial process (Grünewald and Torriti, 2013). Industrial and iron steel plants are associated with interruptible programmes, which consist of bilateral agreements between large industrial usage manufacturers and utilities to reduce power demand at scheduled times when generation and transmission costs 
are particularly high for the grid. These programmes have enabled significant system cost reductions in Europe (Torriti et al, 2010) and Asia (Vivoda, 2010). For the same reason, DSM has significant effects on system costs for the high industrialisation scenario, whose costs after 2035 are remarkably close to those of a medium industrialisation scenario. With regards to new renewables, from the Nigerian Electricity Regulatory Commission, which in 2016 established the second wave of regulated prices to be paid to licensed electricity generation companies in providing electricity to distribution and retailing companies. These include Onshore wind (33.43 Nigerian Naira per MWh), ground mounted PV (92.19 Nigerian Naira per MWh), Small hydro (<30 MW at 32.00 Nigerian Naira per MWh) and Biomass (37.35 Nigerian Naira per MWh). The connection costs of standby generation are considered taking also into account a replacement ratio of the existing standby generation fleet. Overall, for the high industrialisation scenario, DSM would bring about cumulative benefits of around 7 billion USD by 2050 as a net difference between additional costs of operating the grid with or without DSM implementation. It should be emphasised the highest savings correspond not only to higher levels of industrialisation, but also to higher penetration of renewable sources of electricity. This is because industrialisation will foster not only DSM, but also renewable energy generation.

Figure 8 here

\section{Conclusions}

This paper highlights the nexus between future industrialisation, electrification and DSM development in Nigeria. Industrialisation can facilitate further electrification and, at the same time, 
electrification can underscore improved industrial development. It is argued that the two processes are mutually beneficial for the Nigerian electricity system since the presence of industrial loads will increase demand for electricity, but also contribute to higher demand flexibility. This is because industrial end-users are likely to engage in DSM programmes which remunerate planned interruptions of electricity demand or even load shifting on a relatively short notice (e.g. day-ahead or even hour-ahead). Flexible industrial demand through DSM benefits the market as it: (i) provides relief to the grid at times of peak demand; (ii) allows the integration of renewable sources of energy; and (iii) creates additional revenue streams for both utilities and end-users. In turn, the expansion of industrial electricity usage will increase pressure for grid reliability and provide financial opportunities for transmission grid development and especially low-voltage distribution networks where industrial plants will be located.

An increase in industrialisation will trigger a more active and dynamic presence of large end-users through DSM. Industrial end-users will not be only the passive recipients of electricity form the grid, but will engage in load shifting and stand-by generation activities which will create additional revenue opportunities for them. This paradigmatic shift from passive end-users to an active industrial demand side is based on the assumption that most DSM activity will originate from industrial consumers. However, households and commercial users own stand-by generation in the form of diesel generators and small-size battery storage. In terms of aggregate volumes, residential electricity demand is expected to increase in the future (Sambo, 2008).

Previous industrialisation waves in Nigeria and in other developing countries suggest that these processes do not happen in isolation and require substantially prolonged investments by the state. It should be clarified that increasing DSM will not per se trigger or even facilitate industrialisation as the primary activities on industrial end-users are not to provide flexible demand to the electricity grid. However, to an increase in industrialisation could correspond a higher penetration of DSM 
measures, with resource planning to avoid unexpected interruptions which lead to temporary loss of production, idled labour force and potentially even damage to electrical equipment.

Wolde-Rufael (2006) acknowledges that electricity is not necessarily a panacea for socio-economic challenges that Africa faces. However, with attention to the complexity of establishing correlation between energy consumption and development indicators he presents evidence for a significant relationship between electricity consumption and GDP per capita.

The Government set out to invest $\$ 2.6$ billion up to 2020 in institutional funding for near-term investment in transmission infrastructure (Industrial Trade Administration, 2016). Annual capital expenditure in the distribution sector is set at $\$ 370$ million - some of which may be devolved to areas with mostly industrial users. What could the Nigerian government do to set the conditions for DSM deployment? Section 2 highlighted some of the challenges associated with DSM implementation in developing countries, including awareness of energy efficiency and lack of auditing for commercial and industrial users. The main recipients of these financial mechanisms are almost exclusively utilities. It is assumed that utilities will face costs due to the absence of technological investments in DSM. If Nigeria is to follow the example of Brazil (as mentioned in Section 3), for example, then losses from capital costs, installations and planning DSM should be recovered under mechanisms such as cost recovery mechanisms, lost revenue mechanisms and shared savings incentive mechanisms based on performance. This is the key idea behind the financial schemes for DSM which have been set in place not only in Brazil, but also Japan, Australia, Mexico and India, The incentives associated with financial schemes become critical in an investment environment which tends to be paralysed around issues of quality of supply and balancing of demand and supply.

Cost recovery mechanisms are designed to eliminate the business incentive to underspend on DSM programmes. They allow utilities to recover the capital and installation costs. The utilities costs for DSM are usually "expensed," approved by regulators and sometimes amortised over several years. 
Interest is charged on under -or over- recoveries. Because under cost recovery mechanisms the utilities costs are amortised over several years, the economic significance of load shifting is lost. In other words, the behavioural learning on the consumer side is very limited.

Lost revenue mechanisms pay utilities back for the direct losses that they experience due to decreases in electricity sold. Lost revenues associated with reductions in total amounts of sold electricity are partly offset by a reduction or avoidance of variable costs -e.g. the cost of fuel for power plants. The typology of opportunity costs often included in lost revenue mechanisms include recovery of all of the revenues that utilities would have benefited from had they not promoted DSM programmes. Lost revenue mechanisms are designed to make DSM revenue-neutral and eliminate the incentive to minimise savings from DSM. This leaves the utility financially indifferent to the level of DSM achieved. As a practical example, in a given year, the utility calculates the amount of volume or kWh losses due to its own DSM programmes. This must be calculated net of any efficiency trends occurring independently of DSM, since sales losses due to other factors would have been experienced anyway.

Lost revenue mechanisms are designed to make DSM revenue-neutral and eliminate the incentive to minimise savings from DSM. This leaves the utility financially indifferent as to the level of DSM that is achieved. The utility gets reward for its DSM losses. If services delivered go down as a result of DSM activities, all other things being equal, rates will go up so that costs may be recovered. This means that all consumers pay for lack of responsiveness. Instead, it would be much preferable if only the least responsive consumers had to pay.

Shared Savings Incentive Mechanisms are designed to provide rewards to utilities based on the effectiveness of socially beneficial DSM. These mechanisms can compensate for energy savings associated with DSM by making it possible for the utility to share the consumer net benefits from DSM programmes. In principle, penalties for underperformance can also be part of a Shared Savings Incentive Mechanism, but have not been implemented. This creates a business case for sustainable 
DSM initiatives that promote energy efficiency on an evolving, adaptive, multi-year basis. A precondition of Shared Savings Incentive Mechanisms is that the regulator determines DSM target levels on utilities. This can represent a forecasting problem under different (e.g. temperature) conditions that might induce peak loads. For instance, a share or percentage of actual DSM net benefits over the target level determined by the regulator can be apportioned to the utility in the form of a positive rate adjustment. In other words, the aim of Shared Savings Incentive Mechanisms is to remunerate a utility to achieve more than the targets approved by the regulator. As a practical example, in a given year, the utility calculates the amount of volume or kWh losses due to its own DSM programmes. This must be calculated net of any efficiency trends occurring independently of DSM, since sales losses due to other factors would have been experienced anyway.

The paper has also conceptual implications in terms of the political economy if energy in developing countries. Traditionally, in the economics and political economy literature energy fuels (e.g. oil, coal and electricity) are defined as classic commodity industries. This means that utilities are producerdriven production networks in which the state has some responsibility for infrastructural assets (e.g. transmission networks) and this responsibility decreases depending on the level of privatisation and liberalisation of the markets. Under this traditional view the scope for product differentiation is limited as the relationship between state and private actors is centred mostly on securing access to resources and finding cost-effective ways of transmitting and distributing the resources across a variety of users. Correspondingly, this model views electricity demand as an exogenous variable since in modern, centralised energy production systems the consumer is located at the end of the wire (Bridge, 2010). In a country like Nigeria, where the resources for electricity generation in principle are plentiful and economical, the emphasis should move to how electricity is managed based on increasing demand from a growing population and economy. The traditional approach has certainly failed in delivering both appropriate market balancing between demand and supply, and institutionalised growth of infrastructure (Subair \& Oke, 2008). At the expense of oversimplification, over the years both the natural monopoly and the liberalised market approaches have not delivered 
significant improvements to energy systems in Nigeria (Kennedy-Darling, et al, 2008). This

undermines the tendency to a state versus market dichotomous approach that has dominating thinking on resolving the electricity crisis. What has traditionally been a venue for discussion on either separation or overlap between the state and the market could become the space for a paradigmatic shift to a more dynamic interpretation of institutions and businesses or public and private sectors.

\section{Acknowledgements}

This work was supported by the Engineering and Physical Sciences Research Council (grant number $\mathrm{EP} / \mathrm{P000630/1).}$

\section{References}

ADEME - World Energy Council and French Environment and Energy Management Agency (2004). "Energy Efficiency: A Worldwide Review", London, United Kingdom, Technical Report, July 2004.

Adenikinju, A. F. (1998). Productivity growth and energy consumption in the Nigerian manufacturing sector: a panel data analysis. Energy policy, 26(3), 199-205.

Adenikinju, A. F. (2003). Electric infrastructure failures in Nigeria: a survey-based analysis of the costs and adjustment responses. Energy policy, 31(14), 1519-1530.

Adenikinju, A. F. (2005). Analysis of the cost of infrastructure failures in a developing economy: The case of the electricity sector in Nigeria (Vol. 148). Nairobi: African Economic Research Consortium.

Akinbulire, T. O., Oluseyi, P. O., \& Babatunde, O. M. (2014). Techno-economic and environmental evaluation of demand side management techniques for rural electrification in Ibadan, Nigeria. International Journal of Energy and Environmental Engineering, 5(4), 375-385.

Akinlo, A. E. (2009). Electricity consumption and economic growth in Nigeria: evidence from cointegration and co-feature analysis. Journal of Policy Modeling, 31(5), 681-693.

Aliyu, A. S., Ramli, A. T., \& Saleh, M. A. (2013). Nigeria electricity crisis: Power generation capacity expansion and environmental ramifications. Energy, 61, 354-367.

Ayodele, A. S, (2001). Improving and Sustaining Power (Electricity) Supply for Socio-economic Development in Nigeria. Accessed 1 March 2017 www.cenbank.org/out/annual/ACZRU/2001.

Azoumah, Y., Yamegueu, D., Ginies, P., Coulibaly, Y., \& Girard, P. (2011). Sustainable electricity generation for rural and peri-urban populations of sub-Saharan Africa: the "flexy-energy" concept. Energy Policy, 39(1), 131-141. 
Bazilian, M. and Onyeji, I., 2012. Fossil fuel subsidy removal and inadequate public power supply: Implications for businesses. Energy Policy, 45, 1-5.

Boshell, F., \& Veloza, O. P. (2008). Review of developed demand side management programs including different concepts and their results. In Transmission and Distribution Conference and Exposition: Latin America, 2008 IEEE/PES, 1-7.

Bridge, G. (2010). Heading 'downstream': Towards a cultural political economy of energy consumption. Energy Subjects: cultural economies of energy consumption, ESRC Seminar, Manchester, March 2010.

Business Day (2017). Privatisation in power sector has failed - Senate May 24 2017. Accessed 17 September 2017. http://www.businessdayonline.com/privatisation-power-sector-failed-senate/

Chete, L.N., Adeoti, J.O., Adeyinka, F.M. and Ogundele, O., (2014). Industrial development and growth in Nigeria: Lessons and challenges (No. 2014/019). WIDER Working Paper. Accessed 17 September 2017. https://www.brookings.edu/wp-content/uploads/2016/07/L2C WP8 Chete-et-al1.pdf

Central Bank of Nigeria (2016). Annual Report and Statement of Accounts 2015, Lagos: Central Bank of Nigeria.

Dada, J.O., (2014). Towards understanding the benefits and challenges of Smart/Micro-Grid for electricity supply system in Nigeria. Renewable and Sustainable Energy Reviews, 38, 1003-1014.

Ebohon, O.J., (1996). Energy, economic growth and causality in developing countries: a case study of Tanzania and Nigeria. Energy Policy 24, 447-453.

Ejiogu, A. R. (2013). A nuclear Nigeria: How feasible is it? Energy Strategy Reviews, 1(4), 261-265.

Energy Commission of Nigeria (2002). National Energy Policy. Abuja: Energy Commission of Nigeria.

Energy Commission of Nigeria (2012). Nuclear Power Development in Nigeria. Accessed 1 March 2017. http://www.energy.gov.ng/index.php?option=com_content\&task=view\&id=62\&ltemid=39

Energy Commission of Nigeria (2014). Draft National Renewable Energy and Energy Efficiency Policy. Abuja: Energy Commission of Nigeria. Accessed 1 March 2017.

http://www.energy.gov.ng/index.php?option=com docman\&task=search result\&ltemid=49.

Energy Sector National Technical Working Group (2009). Report of the vision 2020. Abuja: Energy Sector National Technical Working Group.

Eze, C.U., Agwu, D.D., Uzoechi, L. O. (2016). A new proposed demand side management technique. International Journal of Engineering Sciences \& Emerging Technologies, 8, 271-281.

Federal Government of Nigeria (2016). Report of Nigeria's participation in the United Nations Climate Change Conference (COP-22/CMP-12/CMA1) Marrakech, Morocco, 7-18 2016

http://www.environment.gov.ng/assets/downloads/COP22\%20REPORT\%2022\%20NOV\%202016.pdf

Fishbone, L. G., \& Abilock, H. (1981). Markal, a linear-programming model for energy systems analysis: Technical description of the bnl version. International journal of Energy research, 5(4), 353375.

Gardiner, A. 2016. Prices and costs of EU energy Annex 4: Data for industrial analysis. Accessed 1 March 2017. https://ec.europa.eu/energy/sites/ener/files/documents/annex4_ecofys2016.pdf 
Gellings, C. W. (1985). The concept of demand-side management for electric utilities. Proceedings of the IEEE, 73(10), 1468-1470.

Grünewald, P. and Torriti, J. (2013), Demand response from the non-domestic sector: Early UK experiences and future opportunities. Energy Policy, 61, 423-429.

Ibitoye, F. I., \& Adenikinju, A. (2007). Future demand for electricity in Nigeria. Applied Energy, 84(5), 492-504.

International Energy Agency (2011). Load Management with Demand-Side Management, an overview. Paris: IEA.

International Energy Agency (2015). Energy Statistics of Non-OECD Countries online data service 2015 edition. Paris: IEA.

International Trade Administration (2016). 2016 Top Markets Report Smart Grid Country Case Study: Nigeria. Accessed 1 November 2017

https://www.trade.gov/topmarkets/pdf/Smart_Grid_Nigeria.pdf

Kennedy-Darling, J., Hoyt, N., Murao, K., \& Ross, A. (2008). The energy crisis of Nigeria: an overview and implications for the future. The University of Chicago, Chicago.

Kilby, P (1969). Industrialization in an open economy: Nigeria 1945-1966. CUP Archive.

Loulou, R., Lavigne, D., (1996). MARKAL model with elastic demands: application to greenhouse gas emission control. In: Carraro, C., Haurie, A. (Eds.), Operations Research and Environmental Management. Kluwer, Dordrecht, 201-2220.

Makwe J., AkinwaleY., Atoyebi M. (2012). An Economic Assessment of the Reform of Nigerian Electricity Market. Journal of Energy and Power, 2, 24-32.

Menegaki, A.N. \& Tugcu, C.T. (2016). Rethinking the energy-growth nexus: Proposing an index of sustainable economic welfare for Sub-Saharan Africa Energy Research and Social Science, 17, 147159.

Mukhopadhyay, S. \& Rajput, A. K. (2010). Demand side management and load control-An Indian experience. In Power and Energy Society General Meeting, IEEE (1-5).

Narayan,P. \& R. Smyth (2009). Multivariate Granger causality between electricity consumption, exports and GDP: evidence from a panel of Middle Eastern countries. Energy Policy, 37, 229-236.

National Bureau of Statistics (2012). Annual Abstract of Statistics. Accessed 1 March 2017. http://www.nigerianstat.gov.ng/pdfuploads/annual_abstract_2012.pdf

National Bureau of Statistics (2016). Capital Importation Report Q2 2016. Abuja: Nigerian Bureau of Statistics.

Nigerian Electricity Regulatory Commission (2014). The Potential for Demand Side Management in Nigeria. Technical Workshop on Energy Efficiency and Demand-Side Management, December 3-5, 2014, Dubai.

Ohunakin, O. S., Adaramola, M. S., \& Oyewola, O. M. (2011). Wind energy evaluation for electricity generation using WECS in seven selected locations in Nigeria. Applied Energy, 88(9), 3197-3206. 
Okafor, E.E. (2008). Development crisis of power supply and implications for industrial sector in Nigeria. Journal of Tribes and Tribals, 6(2), 83-92.

Okoro, O. I., \& Chikuni, E. (2007). Power sector reforms in Nigeria: opportunities and challenges. Journal of Energy in Southern Africa, 18(3), 52-57.

OPEC (2011). Annual Statistical Bulletin. Vienna: OPEC.

Presidency of Federal Republic of Nigeria (2010). Roadmap for Power Sector Reform. Accessed 1 March 2017. http://www.nigeriaelectricityprivatisation.com/wpcontent/uploads/downloads/2011/03/Roadmap-for-Power-Sector-Reform-Full-Version

Quaghe, J.Z. (2017). Why Privatization has not Improved Power Supply in Nigeria. Ventures Africa http://venturesafrica.com/why-privatization-has-not-improved-power-supply-in-nigeria/ Accessed 17 September 2017.

Research and Markets (2016). Nigeria Air Conditioner Market (2016-2022). Accessed 1 March 2017. http://www.researchandmarkets.com/research/jpdbjv/nigeria_air

Sambo, A. S. (2008). Matching electricity supply with demand in Nigeria. International Association of Energy Economics, 4, 32-36.

Se4all (2016). Nigeria: Rapid Assessment and Gap Analysis. Sustainable Energy for All. Accessed 1 November 2017, https://www.se4allafrica.org/fileadmin/uploads/se4all/Documents/Country_RAGAs/Nigeria_RAGA_EN_Released.pdf Squalli, J. (2007). Electricity consumption and economic growth: Bounds and causality analyses of OPEC members. Energy Economics 29, 6, 1192-1205.

Subair, K., \& Oke, D. M. (2008). Privatization and trends of aggregate consumption of electricity in Nigeria: An empirical analysis. African Journal of Accounting, Economics, Finance and Banking Research, 3, 18-27.

Steinbuks, J. and Foster, V. (2010). When do firms generate? Evidence on in-house electricity supply in Africa. Energy Economics, 32(3), 505-514.

Templet, P.H. (1999). Energy, diversity and development in economic systems; an empirical analysis. Energy Policy, 30, 223-233

Torriti, J., Hassan, M. G. and Leach, M. (2010). Demand response experience in Europe: policies, programmes and implementation. Energy, 35 (4), 1575-1583.

Torriti, J. (2015), Peak energy demand and demand side response. Routledge Explorations in Environmental Studies. Routledge, Abingdon, pp. 172.

United Nations Industrial Development Organisation (UNIDO) (2015). Sustainable Energy Regulation and Policymaking: Demand Side Management. Accessed 1 November 2017, http://africatoolkit.reeep.org.

Vivoda, V. (2010). Evaluating energy security in the Asia-Pacific region: A novel methodological approach. Energy Policy, 38(9), 5258-5263.

Wolde-Rufael, Y. (2006). Electricity consumption and economic growth: a time series experience for 17 African countries. Energy policy, 34(10), 1106-1114. 
World Bank (2017). World Development indicators. Accessed 1 March 2017.

http://data.worldbank.org/data-catalog/world-development-indicators

Yahaya, Y., Salisu, B.M. and Umar, B., (2015) Electricity supply and manufacturing output in Nigeria: Autoregressive Distributed Lag (ARDL) Bound Testing Approach. Journal of Economics and Sustainable Development, 6(17), pp.7-19.

Zhong, J., Kang, C., \& Liu, K. (2010). Demand side management in China. In Power and Energy Society General Meeting, 2010 IEEE (1-4). 